\title{
Pengaruh Kerja Sama Orang Tua Siswa Dengan Guru Terhadap Pendidikan Agama Islam Di MTS Muhammadiyah 03 Sedayulawas Lamongan
}

\author{
Maftuhah \\ Sekolah Tinggi Ilmu Tarbiyah Muhammadiyah Paciran Lamongan, Indonesia \\ E-mail: kireina1704@gmail.com
}

Abstract: The purpose of this study is to determine whether there is an effect of cooperation between parents and teachers on Islamic religious education at MTs Muhammadiyah 03 Sedayulawas Lamongan. This research is a qualitative research with a background at MTs Muhammadiyah 03 Sedayulawas Lamongan. Data collection was carried out through observation, interviews / interviews, and documentation. This research uses a qualitative descriptive approach, so the presence of researchers in the field is very important. Researchers act directly as instruments and as data collectors from in-depth observations and are actively involved in research. Data in the form of words were obtained from informants, while additional data was in the form of documents. Data analysis is done by examining existing data, then reducing data, presenting data and drawing conclusions and the final stage of data analysis is to validate the data by using the accuracy and persistence of triangulation observations. The results showed: (1) The cooperation of parents and teachers. (2) Efforts to improve Islamic Religious Education. (3) The effect of cooperation between parents and teachers on Islamic Religious Education.

Keywords: cooperation of parents, teachers, Islamic education

\section{Pendahuluan}

Mengingat pentingnya pelaksanaan pendidikan agama islam dalam kehidupan keluarga yang merupakan titik awal pengalaman pendidikan pada anak,maka islam memandang keluarga bukan sebagai persekutuan hidup terkecil 
saja,tetapi lebih dari itu yaitu sebagai lembaga hidup manusia yang dapat memberikan kebahagian di Dunia dan akhirat. Di sinilah pentingnya orang tua sebagai pendidik kodrati yang mempunyai tugas dan kewajiban untuk merawatnya, memberikan perlindungan,membesarkan dan mendidiknya agar kelak menjadi orang dewasa yang berbudi pekerti baik.

Sedangkan untuk mengembangkan dan meningkatkan daya intelektual serta daya tangkap yang sebelumnya telah terbina dalam keluarga, termasuk juga upaya pengembangan dan pendidikan agamanya, orang tua memberikan kepercayaan kepada sekolah untuk meneruskan pembinaan pendidikan yang telah diletakkan dasar-dasarnya dalam lingkungan keluarganya.

Adanya sekolah bukan berarti pihak keluarga melepaskan tanggung jawab pendidikan anaknya 100\% kepada sekolah tersebut, tetapi tugas mendidik anak secara lengkap masih ada dan tetap berlangsung dalam keluarga. Dengan demikian jelaslah, bahwa keluarga dan sekolah adalah dua lembaga pendidikan yang hendaknya bergandengan tangan untuk bekerja sama dalam melakukan tugas yang sama yaitu mendidik anak.

Sebagaimana pendapat crow and crow dalam bukunya H. M. Arifin yang menyatakan bahwa: "Tak ada kerja sama antara dua lapangan yang paling diperlukan daripada kerja sama antara rumah dan sekolah". Orang tua dan guru harus mengerti dan mengetahui tentang anak yang pendidikannya menjadi tanggung jawab anak dapat memperoleh keuntungan daripada pola perkembangan pendidikan" (Arifin,1978,110).

Dari pendapat di atas dapat disimpulkan, bahwa kerja sama yang baik antara orang tua dan guru adalah faktor yang ikut menentukan berhasilannya pendidikan.

Dengan demikian, kerja sama ini hendaknya diwujudkan dalam bentuk adanya komunikasi antara orang tua dan guru, supaya aktivitas belajar anak berjalan lancar serta dapat tercapai tujuan pendidikan.

Adapun yang menjadi tujuan pendidikan agama islam di Madrasah Tsanawiyah Muhammadiyah 03 Sedayulawas Lamongan, sebagaimana yang tertuang dalam GBHN adalah sebagai berikut : 'Pendidikan nasional berdasarkan 
Pancasila dan bertujuan meningkatkan ketaqwaan terhadap Tuhan yang Maha Esa, kecerdasan, ketrampilan, mempertinggi budi pekerti, memperkuat kepribadian dan mempertebal semagat kebangsaan agar dapat menummbuhkan manusia pembangunan yang dapat membangun dirinya sendiri serta bersama-sama bertanggung jawab atas pembangunan bangsa." ( Daradjat, dkk,1992;88)

Bertolak dari teori di atas, jika melihat sebagian besar masyarakat yang menjadi obyek penelitian adalah nelayan sebagai mata pencaharian utamanya, ternyata rata-rata mereka kurang begitu memperhatikan terhadap pendidikan anaknya.

Melihat kondisi demikian,perlu kiranya penulis mengangkat suatu permasalahan dalam rangka menyusun skripsi dengan judul Pengaruh Kerja Sama Orang Tua Siswa Dengan Guru Terhadap Pendidikan Agama Islam Di MTS Muhammadiyah 03 Sedayulawas Lamongan.

Berdasarkan uraian latar belakang yang telah dikemukakan diatas, maka penulis dapat merumuskan permasalahan pokok sebagai berikut:

1. Bagaimanakah keadaan kerja sama orang tua siswa dengan guru di MTs Muhammadiyah 03 Sedayulawas Lamongan Tahun pelajaran 2019/2020?

2. Bagaimanakah keadaan pendidikan agama islam di MTs Muhammadiyah 03 Sedayulawas Lamongan Tahun pelajaran 2019/2020?

3. Adakah pengaruh kerja sama orang tua siswa dengan guru terhadap pendidikan agama islam di MTs Muhammadiyah 03 Sedayulawas Lamongan Tahun pelajaran 2019/2020?

\section{Kajian Teori}

Orang tua pada permulaan adanya manusia menjalankan pendidikan bagi anak-anaknya. Orang tua yang bertugas menanamkan dan mengarahkan anak kepada hal positif bagi pertumbuhan jasmani dan rohani.

Setelah anak meningkat kepada kemajuan lalu orang tua menyerahkan tugas tersebut kepada guru di sekolah. Perilaku pendidikan informal dan formal 
memerlukan kerjasama antara guru dan orang tua, karena hal itu sangat penting untuk kelancaran pendidikan anak serta dapat mencapai tujuan sesuai yang diharapkan.

Menurut teori pendidikan orang tua sebagai penanangung utama terdapat pendidikan anak-anaknya, karena anak lahir dan hidup dalam lingkungan rumah tangga. Sehingga mereka diasuh, dididik dan dirawat dengan penuh kasih sayang dan tanggung jawab. Karena keterbatasan kemampuan dan pengetahuan orang tuanya dalam mendidik anak-anaknya dalam tingkat yang lebih tinggi, maka tugastugas kependidikan ini dilimpahkan kepada guru di sekolah. Hal tersebut telah sesuai dengan firman Allah dalam surat al-maidah ayat 2 yang berbunyi:

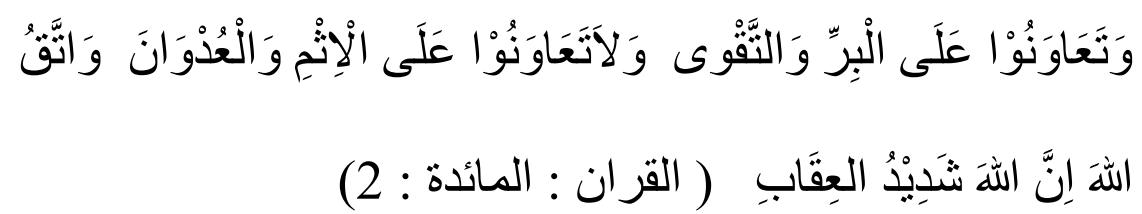

Artinya: “ ..... dan tolong-menolonglah kamu terhadap usaha-usaha kabajikan dan usaha memelihara diri dari segala yang memberatkan diri dan janganlah kamu bertolong-menolong terhadap dosa dan permusuhan ......

QS.Al Maidah ayat2 " ( QS: Al-Maidah: 2)

Berpijak dari landasan di atas telah jelas bahwa kerja sama disini sangat dibutuhkan bagi perkembangan anak, karena untuk mencapai segala sesuatu yang diharapkan perlu diciptakan kerjasama yang baik.

\section{Metode Penelitian}

Penulis akan memilih lokasi penelitian pada sekolah MTs Muhammadiyah 03 Sedayulawas Lamongan.

Adapun subyek penelitiannya adalah kepala sekolah yaitu Bapak Ahmad Farich, S.Pd.I., guru Pendidikan Agama Islam dan siswa.

Penelitian ini menggunakan pendekatan berparadigma Deskriptif-Kualitatif.

Dalam penelitian ini penulis menggunakan tiga macam teknik pengumpulan data yaitu metode observasi, metode interview, dan metode dokumentasi. 


\section{Paparan Dan Pembahasan Data Hasil Penelitian}

Kerja sama orang tua siswa dengan guru di MTs Muhammadiyah 03 Sedayulawas Lamongan dari hasil observasi dan interview dengan guru agama, dapatlah dikemukakan sebagaimana dalam uraian berikut.

Menurut Bapak Ahmad Farich, S.Pd.I. bahwa kerjasama orang tua siswa dengan guru dilaksanakan dengan melalui :

a. Pertemuan antara kepala sekolah, para guru, orang tua siswa dan pengurus sekolah. Hal ini dilakukan pada awal masuk tahun ajaran baru,

b. Pertemuan wali murid atau pengambilan raport yang di adakan tiga bulan sekali dan enam bulan sekali.

c. Mengadakan surat panggilan kepada orang tua siswa. Hal ini dilakukan pada waktu yang sangat diperlukan.

Analisis pengaruh kerja sama orang tua dengan guru terhadap pendidikan agama Islam untuk menganalisa tersebut Penulis menggunakan rumus Produc Moment. Adapun langkah-langkahnya adalah sebagai berikut. Sebagai langkah persiapan dalam menganalisa data, maka perlu diadakan perhitungan tentang kategori dari masing-masing variabel.

Dengan demikian, setiap variabel terdapat kategori tinggi dan rendah. Berikut adalah tabel Tabulasi pengaruh kerja sama orang tua dengan guru terhadap pendidikan agama Islam di MTs Muhammadiyah 03 Sedayulawas Lamongan.

Tabel Tabulasi

Pengaruh Kerja Sama Orang Tua Dengan Guru Terhadap Pendidikan Agama Islam

\begin{tabular}{|c|l|c|c|c|c|c|}
\hline NO. & \multicolumn{1}{|c|}{ Nama Responden } & $\mathbf{x}$ & $\mathbf{x 2}$ & $\mathbf{y}$ & $\mathbf{y 2}$ & $\mathbf{x y}$ \\
\hline 1 & Afif Anshori & 45 & 2025 & 45 & 2025 & 2025 \\
\hline 2 & Agus Setiawan & 43 & 1849 & 43 & 1849 & 1849 \\
\hline
\end{tabular}




\begin{tabular}{|c|c|c|c|c|c|c|}
\hline 3 & Ahmad Taufiq & 43 & 1849 & 45 & 2025 & 1935 \\
\hline 4 & Akas Raharjo & 45 & 2025 & 45 & 2025 & 2025 \\
\hline 5 & Bagus Vinaldi & 44 & 1936 & 45 & 2025 & 1980 \\
\hline 6 & Candra K & 43 & 1849 & 43 & 1849 & 1849 \\
\hline 7 & Chosdian W & 41 & 1681 & 43 & 1849 & 1763 \\
\hline 8 & Elvi Widiastuti & 45 & 2025 & 45 & 2025 & 2025 \\
\hline 9 & Ewa Afifudin & 44 & 1936 & 45 & 2025 & 1980 \\
\hline 10 & Genduk Fairotul & 44 & 1936 & 45 & 2025 & 1980 \\
\hline 11 & Gita afidhotul & 43 & 1849 & 45 & 2025 & 1935 \\
\hline 12 & Genduk Fairotul & 45 & 2025 & 45 & 2025 & 2025 \\
\hline 13 & Gita & 42 & 1764 & 43 & 1849 & 1806 \\
\hline 14 & Ike Devi & 41 & 1681 & 45 & 2025 & 1845 \\
\hline 15 & Khoirul Rozikin & 45 & 2025 & 45 & 2025 & 2025 \\
\hline 16 & Lutfi Nur Aidi & 43 & 1849 & 41 & 1681 & 1763 \\
\hline 17 & Miftakhul J & 45 & 2025 & 43 & 1849 & 1935 \\
\hline 18 & Muh Yayan & 45 & 2025 & 41 & 1681 & 1845 \\
\hline 19 & M Aldi & 44 & 1936 & 45 & 2025 & 1980 \\
\hline 20 & Moh. Riza Fany & 43 & 1849 & 45 & 2025 & 1935 \\
\hline 21 & Nur Huda & 45 & 2025 & 43 & 1849 & 1935 \\
\hline 22 & Nur isnia $A$ & 45 & 2025 & 45 & 2025 & 2025 \\
\hline 23 & Nur Atikah & 42 & 1764 & 45 & 2025 & 1890 \\
\hline
\end{tabular}




\begin{tabular}{|c|l|c|c|c|c|c|}
\hline 24 & Nur Faridah & 45 & 2025 & 45 & 2025 & 2025 \\
\hline 25 & Riski Nanda & 45 & 2025 & 45 & 2025 & 2025 \\
\hline 26 & Rohmatul A & 45 & 2025 & 45 & 2025 & 2025 \\
\hline 27 & Rohmatul J & 41 & 1681 & 45 & 2025 & 1845 \\
\hline 28 & Roichatul & 45 & 2025 & 45 & 2025 & 2025 \\
\hline 29 & Setyo Caesaria & 45 & 2025 & 45 & 2025 & 2025 \\
\hline 30 & Zahrotul Jannah & 45 & 2025 & 45 & 2025 & 2025 \\
\hline \multicolumn{2}{|l|}{ JUMLAH } & 1316 & 57784 & 1330 & 59006 & 58370 \\
\hline
\end{tabular}

Keterangan :

$\mathrm{x}$ : pengaruh kerja sama orang tua dengan guru

y ; pendidikan Agama Islam

Dari tabel diatas dapat diketahui ada tidaknya pengaruh kerja sama orang tua dengan guru terhadap pendidikan agama Islam dengan menggunakan rumus Koefisien Product moment (rumus 3) sebagai berikut:

$$
\begin{aligned}
& \mathrm{r}_{\mathrm{xy}}=\frac{\mathrm{N} \sum \mathrm{XY}-\left(\sum \mathrm{X}\right)\left(\sum \mathrm{Y}\right)}{\sqrt{ }\left\{\mathrm{N} \sum \mathrm{X}^{2}-\left(\sum \mathrm{X}\right)^{2}\right\}\left\{\mathrm{N} \sum \mathrm{Y}^{2}-\left(\sum \mathrm{Y}\right)^{2}\right\}} \\
& \mathrm{r}_{\mathrm{xy}}=\frac{30 \times 58370-(1316)(1330)}{\sqrt{\left\{30 \times 57784-1316^{2}\right\}\left\{30 \times 59006-1330^{2}\right\}}} \\
& \mathrm{r}_{\mathrm{xy}}=\frac{1751100-1750280}{\sqrt{(1733520-1731856)(1770180-1768900)}}
\end{aligned}
$$




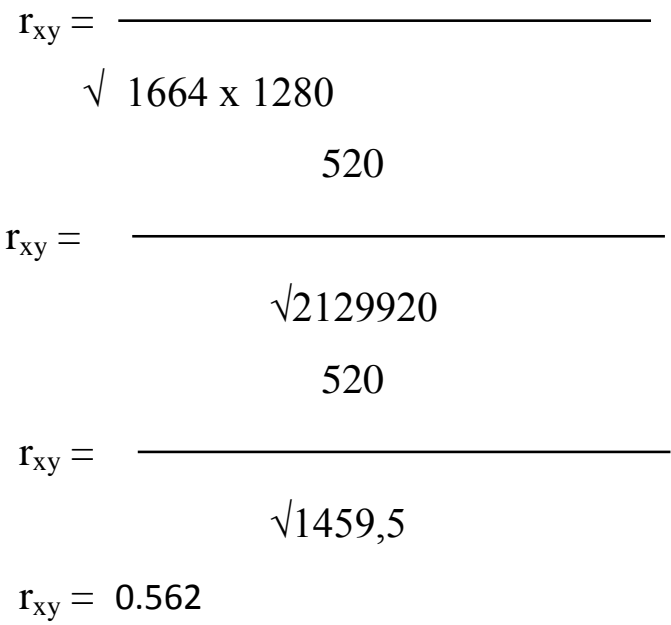

Dari hasil perhitungan dapat disimpulkan bahwa diperoleh nilai indeks Korelasi dengan uji statistic product moment $\left(\mathrm{r}_{\mathrm{xy}}\right)=0,562$, sedangkan pada table " $\mathrm{r}$ " product moment $\mathrm{N}=30$ pada taraf signifikansi $1 \%$ diperoleh nilai 0,361 dan pada taraf signifikansi $5 \%$ diperoleh nilai 0. 463. Dengan demikian dapat diketahui bahwa $\mathrm{r}_{\mathrm{xy}}$ menurut hasil analisa lebih besar daripada harga " $r$ " pada tabel harga kritik dari $\mathrm{r}$ product moment $(0,562>0,463)$ maka hipotesa kera $(\mathrm{H} 1)$ dapat diterima.

Kemudian besarnya $\left(r_{\mathrm{xy}}\right)=0,562$ nilai tersebut terletak diantara $0,40-0,70$ sebagaimana pedoman kreteria di bawah ini.

Kurang dari 0,20 hubungan mudah sekali, lemah sekali.

$0,20-0,40$ hubungan mudah tapi pasti

0,40 - 0,70 hubungan cukup berarti

$0,70-0,90$ hubungan yang tinggi kuat.

Lebih dari 0,90 hubungan sangat tinggi, kuat sekali dapat diandalkan.

Berdasarkan kriteria di atas, maka dapat diketahui bahwa pengaruh kerjasama orang tua murid dengan guru terhadap pendidikan Agam Islam di MTs Muhammadiyah 03 Sedayulawas Lamongan mencapai tingkat hubungan cukup berarti.

Dengan demikian bahwa Hipotesa Kerja ( H1) yang telah dikemukakan oleh penulis benar adanya bahwa kerjasama orang tua siswa dengan guru terhadap pendidikan agam Islam di MTs Muhammadiyah 03 Sedayulawas Lamongan 
mempunyai pengaruh antara keduanya walupun hanya mencapai tingkat hubungan cukup berarti.

\section{Kesimpulan}

Berdasarkan pembahasan tentang "Pengaruh Kerja Sama Orang Tua Siswa Dengan Guru Terhadap peningkatan Pendidikan Agama Islam”. Dilanjutkan dengan penyajian data dan analisa data yang ada, maka dapat disimpulkan sebagai berikut:

1. Kerja sama yang baik antara orang tua siswa dengan guru adalah faktor yang ikut menentukan berhasilnya pendidikan.

2. Pendidikan Agama Islam adalah penentuan kepribadian, tingkah laku dan prestasi kepada anak didik yang sesuai dengan agama Islam.

3. Bahwa pengaruh kerja sama orang tua siswa dengan guru terhadap pendidikan Agama Islam di MTs Muhammadiayah 25 Sedayulawas, Mencapai tingkat hubungan cukup berarti. Hal ini dapat dibuktikan dari hasil perhitungan Koefissien Product moment yang nilai tersebut terletak di antara 0,40-0,70 . tiap item yang telah dipersentasikan, jawaban yang paling banyak adalah usaha yang dilakukan telah berjalan dengan baik.

\section{Daftar Rujukan}

Anas Sudijono. 1992. Pengantar Statistik Pendidikan, Cet. 4, Jakarta: Rajawali Pers

A. Tabrani Rusyan, Atang Kusdinar, Zaenal Arifin, 1992. Pendekatan Dalam Proses Belajar Mengajar, Bandung: PT. Remaja Rosdakarya

A. Hamid, Syarif, 1994. Pengantar Kurikulum, Pasuruan: PT. Garoeda Buana Indah

Ahmad Rohani, M, Abu Ahmadi, 1990. Pedoman Penyelenggaraan Administrasi Pendidikan Sekolah, Jakarta: Bumi Aksara

Cece Wijaya, Djadja Djadjufi, A., Tabrani Rusyan, 1991. Upaya Pembaharuan Dalam Pendidikan dan Pengajaran, Bandung: Remaja Rosdakarya

Dali Gulo, Kamus Psikologi, Cet. 1, 1982. Bandung:Tonis 
Maftuhah

Departeman Agama RI, 1984/1985. Administrasi Pendidikan, Jakarta: Direktorat Jendral Pembinaan Kelembagaan Agama Islam

M. Arifin, 1977. Hubungan Timbal Balik Pendidikan Agama di Lingkungan Sekolah dan Keluarga, Jakarta: PT. Bulan Bintang

I.B. Netra, 1974. Statistik Inferensial, Surabaya: Usaha Nasional

Imansyah Alipandie, 1984. Didaktik Metodik Pendidikan Umum, Srabaya

Keputusan Mendikbud, No. 060/U/1993, Kurikulum Pendidikan Dasar GBPP - SLTP, Mata Pelajaran Pendidikan Agama Islam, Jakarta: Depdikbud

Lexy J. Moleong, 1991. Metodologi Penelitian Kualitatif, Bandung: PT. Remaja Rosdakarya

M. Sastroprojo, 1987. Kamus Istilah dan Umum, Sutabaya: Usaha Nasional

M. Ngalim Purwanto, 1992. Psikologi Pendidikan, Bandung: PT. Remaja Rosdakarya

Muhammad Ali, 1984. Penelitian Pendidikan Prosedur dan Strategi, Badung: PT. Angkasa

Ny. Roestiyah N.K., 1986. Masalah-masalah Ilmu Keguruan, Jakarta: PT. Bina Aksara

Suwarno, 1985. Pengantar Umum Pendidikan, Jakarta: Aksara Baru

Slameto, 1991. Belajar dan Faktor-faktor yang Mempengaruhinya, Jakarta: Rineka Cipta 